\title{
Predicting The Data For Security Using Rjb23 Algorithm
}

\author{
R.Jaichandran ${ }^{1}$, Dr. Avinash Sharma ${ }^{2 * *}$, K.L.Shunmuganathan ${ }^{3}$,Rebin \\ Baby $^{4}$, ArjunKs ${ }^{5}$,and Anil Das ${ }^{6}$ \\ 1,3,4,5,6 Department Of Computer Science And Engineering \\ Aarupadai Veedu Institute Of Technology \\ Vinayaka Mission'S Research Foundation \\ Paiyanoor-603 104, Tamil Nadu, India. \\ ${ }^{1}$ rjaichandran@avit.ac.in, ${ }^{3}$ klsnathan@avit.ac.in, ${ }^{4}$ rebinbab33@gmail.com, \\ 5anju56365636@gmail.com, ${ }^{6}$ anilkanjikulam@gmail.com
}

\author{
${ }^{2}$ Professor, CSE Department, M.M. Deemed to be University, Mullana, Haryana, India, 133207 \\ asharma@mmumullana.org \\ Corresponding Author: Dr. Avinash Sharma ${ }^{2 * *}$
}

\begin{abstract}
-
The current world is information world; without this information can't make due in present stage. This information created more from web-based media; this media information is public information; This public information did not have well security; so we applying the proposed method and it has 3 steps; 1. Using prime numbers in quadratic equations; 2. Prime and non-negative integer number used to swap the numbers; 3. Column operations execution; The new method gives well security when contrast to Salsa method.
\end{abstract}

Keywords: RJB23, Prime, Salsa, Encryption, Decryption.

The current world is information world; without this information can't make due in present stage. This information created more from web-based media; this media information is public information; This public information did not have well security; so to conquer this matter we apply the Salsa strategy. This strategy effectively hack the information from the programmers. The additional rotations XOR for ChaCha is fault attack [1]. This author is used new hash concept for key guessing and halting condition[2].Author was introduced the bricklayer attack for analysis of ChaCha [3]. They mainly focus the security for Double A [4]. They made new design for secure fast and flexible algorithm [5]. SRB18 method used to give security for data [6]. SRB21 method used to give security for data [7]. CBB21 method used to provide security for data [8].CBB22 method used to provide security for data[9].Introduced the new method RJB23( Rajaprakash Jaichandran and Bagath Basha) 23 for this 
problem.

\section{METHODS}

- RJB23 security method are discuss in Table 1 and Table2.

\section{ENCRYPTION}

- "EM is a analyzed matrix. [10]"

\section{"Equation (1)"}

$" \mathrm{p}=2, \mathrm{q}=3$,

$\mathrm{r}=7$ "'EM=36855654"

"Pairs $(3,6),(8,5),(5,6)$ and $(5,4) . "$

"Pair-1(3, 6)"

$$
\mathrm{EM}=\left(\begin{array}{lll}
102 & 103 & 104 \\
106 & 105 & 102 \\
105 & 110 & 108
\end{array}\right)
$$

"Pair-2(8, 5)"

$$
\mathrm{EM}=\left(\begin{array}{lll}
102 & 103 & 104 \\
106 & 105 & 108 \\
105 & 110 & 102
\end{array}\right)
$$

"Pair-3(5, 6)"

$$
\mathrm{EM}=\left(\begin{array}{lll}
102 & 103 & 104 \\
106 & 105 & 105 \\
108 & 110 & 102
\end{array}\right)
$$

"Pair-4(5, 4)"

$$
\mathrm{EM}=\left(\begin{array}{lll}
102 & 103 & 104 \\
106 & 105 & 105 \\
108 & 110 & 102
\end{array}\right)
$$

"Equation (2): $E^{n *} \mathbf{M}^{\prime \prime}$

"EB = 9 is $3,3 "$

"EB=3 is 3, 9"

"Pairs (3,3), (3,9)"

Pair-1 $(3,3)$ 


$$
\mathrm{EB}=\left(\begin{array}{lll}
102 & 103 & 104 \\
106 & 105 & 105 \\
108 & 110 & 102
\end{array}\right)
$$

Pair-2(3,9)

$$
\mathrm{EB}=\left(\begin{array}{lll}
102 & 103 & 104 \\
102 & 105 & 105 \\
108 & 110 & 106
\end{array}\right)
$$

"Equation (3)"

$$
\mathrm{CA}=\left(\begin{array}{lll}
104 & 103 & 102 \\
105 & 105 & 102 \\
106 & 110 & 108
\end{array}\right)
$$

TABLE 1. RJB23 Secure Encryption

\begin{tabular}{|c|l|}
\hline STEPS & \multicolumn{1}{|c|}{ RJB23 SECURE ENCRYPTION } \\
\hline i & "The data analyzed from social data". \\
\hline ii & "The data will form a matrix". \\
\hline iii & "EM $=\left(-p \pm \sqrt{ }\left(p^{2}\right)-4 q r\right) / 2 q$. whereEMisencryptedmatrix"(1) \\
\hline iv & "To form a single row for merged numbers". \\
\hline v & "To form a pair from left to right from Step 4". \\
\hline vi & "All pair could be swapped cell values from given matrix". \\
\hline vii & "EB=E * $\begin{array}{l}n(2) \\
\text { where EB is encryption matrix B." }\end{array}$ \\
\hline viii & "Identify the prime values multiply by the M for order \\
\hline of matrix". \\
\hline x & "E and $\mathrm{M}$ will swap in a matrix EB". \\
\hline
\end{tabular}

TABLE 2. RBJ23 Secure

Decryption

\begin{tabular}{|c|l|}
\hline STEPS & \multicolumn{1}{|c|}{ RJB23 SECURE DECRYPTION } \\
\hline i & "CA=C $<->\left(C_{i+(s-t)}\right)(\mathbf{4})$ where CA is Column decrypted matrix" \\
\hline ii & "To analyse theprime in the given matrix". \\
\hline iii & $\begin{array}{l}\text { "DM1 }=D^{n} \\
\text { where DM1 is decryption matrix 1." }\end{array}$ \\
\hline iv & "DM2 $=\left(-p \pm \sqrt{ }\left(p^{2}\right)-4 q r\right) / 2 a$. whereDM2isdecryptedmatrix2" $(\mathbf{6})$ \\
\hline v & "To form a single row for merged numbers". \\
\hline
\end{tabular}




\begin{tabular}{|c|l|}
\hline vi & "To form a pair from right to left from Step 5". \\
\hline vii & "All pair could be swapped cell values from given matrix". \\
\hline
\end{tabular}

4. DECRYPTION

"Equation (4)"

$$
\mathrm{CA}=\left(\begin{array}{lll}
102 & 103 & 104 \\
102 & 105 & 105 \\
108 & 110 & 106
\end{array}\right)
$$

"Equation (5)": $D M 1=D^{n *} \mathbf{M}$

"DM1 = 9 is 3, 3"

"DM1= 3 is $9,3 "$

Pairs $(9,3),(3,3)$

Pair-1 $(9,3)$

$$
\mathrm{DM} 1=\left(\begin{array}{lll}
102 & 103 & 104 \\
106 & 105 & 105 \\
108 & 110 & 102
\end{array}\right)
$$

Pair-2(3,3)

$$
\mathrm{DM} 1=\left(\begin{array}{lll}
102 & 103 & 104 \\
106 & 105 & 105 \\
108 & 110 & 102
\end{array}\right)
$$

"Equation (6)"

"p=2,q=3, r=7"

"DM2 $=(-3 \pm \sqrt{ }(32)-4 * 2 * 7) / 2 * 2 "$

"DM12=(-3 $\pm \sqrt{ } 9-56) / 4 "$

"DM2 $=(-3 \pm \sqrt{ } 47) / 4 "$

"DM2 $=(-3 \pm 6.85565) / 4 "$

"DM2 = 36855654."

"Pair of numbers $(4,5),(6,5),(5,8)$, and $(6,3) . "$

"Pair-1(4, 5)" 
"Pair-2(6, 5)"

$$
\mathrm{DM} 2=\left(\begin{array}{lll}
102 & 103 & 104 \\
106 & 105 & 105 \\
108 & 110 & 102
\end{array}\right)
$$

$$
\mathrm{DM} 2=\left(\begin{array}{lll}
102 & 103 & 104 \\
106 & 105 & 108 \\
105 & 110 & 102
\end{array}\right)
$$

"Pair-3(5, 8)"

$$
\mathrm{DM} 2=\left(\begin{array}{lll}
102 & 103 & 104 \\
106 & 105 & 102 \\
105 & 110 & 108
\end{array}\right)
$$

"Pair-4(6, 3)"

$$
\mathrm{DM} 2=\left(\begin{array}{lll}
102 & 103 & 104 \\
105 & 105 & 102 \\
106 & 110 & 108
\end{array}\right)
$$

\section{CONCLUSION}

The current world is information world; without this information can't make due in present stage. This information created more from web-based media; this media information is public information; This public information did not have well security; so we apply the RJB23 method and it has 3 steps; 1 . Using prime numbers in quadratic equations; 2 . Prime numbers and non-negative integer number used to swap the numbers; 3 . Column operations execution; The RJB23 method gives well security when comparing to Salsa method.

\section{REFERENCES}

[1] P. A. BABU AND J. J. THOMAS: A Practical Fault Attack on ARX-like Ciphers with a Case Study on ChaCha20, Wo. on Fa. Di. and To. in Cr. (2017), 33-40.

[2] S. V. D. KUMAR, S. PATRANABIS, J. BREIER, D. MUKHOPADHYAY, S. BHASIN, A. CHATTOPADHYAY, AND A. BAKS: Freestyle, a randomized version of ChaCha for resisting offline brute-force and dictionary attacks, IE. tr. on In. Fo. and Se. (2018).

[3] A. ADOMNICAI, J. J. A. FOURNIER, AND L. MASSON: Bricklayer Attack: A Side- Channel Analysis on the ChaCha Quarter Round, Pr. in Cr. In., Le. No. in Co. Sc., Sp. 65-84. 
[4] B. MAZUMDAR, S.K. S. ALI AND O. SINANOGLU: Power Analysis Attacks on ARX: An Application to Salsa20, On-. Te. Sy. IE. (2015), 4043.

[5] C. WATT, J. RENNER, N. POPESCU, S. CAULIGI, AND D. STEFAN: CT-Wasm: Type- Driven Secure Cryptography for The Web Ecosystem, Pr. ACM Pr. La. PO. (2019), 77:1-77:29.

[6] C. BAGATH BASHA, S. RAJAPRAKASH: Enhancing The Security Using SRB18 Method of Embedding Computing, Mic. and Mic 103125, (2020).

[7] C. B. BASHA, S. RAJAPRAKASH: Securing Twitter Data Using Srb21 Phase I Methodology, Int. Jou. of Sci. and Tec. Res. 8(12) (2019), 19521955.

[8] C. B. BASHA, S. RAJAPRAKASH: Applying The CBB21 Phase 2 Method For Securing Twitter Analyzed Data, Adv. In Mat. : Sci. Jou. 9(3) (2020), 1085-1091.

[9] C. B. BASHA, S. RAJAPRAKASH, V. V. A. HARISH, M. S. KRISHNA, K. PRABHAS: Securing Twitter Analysed Data Using CBB22 Algorithm, Adv. In Mat. : Sci. Jou. 9(3) (2020), 1093-1100.

[10] C. B. BASHA, K. SOMASUNDARAM: A Comparative Study of Twitter Sentiment Analysis Using Machine Learning Algorithms in Big Data, Int. Jou. of Rec. Tec. and Eng. 8(1) (2019), 591-599.

[11] Somasekar, J. \& Sharma, A. \& Reddy, N. \& Reddy, Y.. (2020). IMAGE ANALYSIS FOR AUTOMATIC ENUMERATION OF RBC INFECTED WITH PLASMODIUM PARASITES-IMPLICATIONS FOR MALARIA DIAGNOSIS. Advances in Mathematics: Scientific Journal. 9. 1221-1230. 10.37418/amsj.9.3.48.

[12] A. SHARMA1 AND J. SOMASEKAR "Contrast Image Construction Technique for Medical Imaging" published in Advances in Mathematics: Scientific Journal (Adv. Math., Sci. J.) vol-9-no-6-2020 (pp 3325-3329)

[13] Rohini Goel, Avinash Sharma, and Rajiv Kapoor, "Object Recognition Using Deep Learning" published in Journal of Computational and Theoretical Nanoscience Vol. 16, 4044-4052, 2019

[14] Santosh, Mamta \& Sharma, Avinash. (2019). A Proposed Framework for Emotion Recognition Using Canberra Distance Classifier. Journal of Computational and Theoretical Nanoscience. 16. 3778-3782. 10.1166/jctn.2019.8250.

[15] Mamta Santosh, Avinash Sharma, "Facial Expression Recognition using Fusion of LBP and HoG Features" published in International Journal of Innovative Technology and Exploring Engineering (IJITEE) ISSN: 2278-3075, Volume-8 Issue-8 June, 2019 